Proceedings of the 2010 Winter Simulation Conference

B. Johansson, S. Jain, J. Montoya-Torres, J. Hugan, and E. Yücesan, eds

\title{
SIMULATING THE SEISMIC PERFORMANCE OF A LARGE-SCALE ELECTRIC NETWORK IN THE U.S. MIDWEST
}

\author{
Edgar C. Portante \\ James A. Kavicky \\ Stephen F. Folga \\ Brian A. Craig \\ Leah E. Talaber \\ Argonne National Laboratory \\ 9700 South Cass Avenue \\ Argonne, IL 60439, USA
}

Gustav R. Wulfkuhle

FEMA Region V

535 South Clark Street, $6^{\text {th }}$ Floor

Chicago, IL 60605, USA

\begin{abstract}
This paper summarizes the methodology and simulation tools used by Argonne National Laboratory to examine the impact that a high-intensity New Madrid seismic event could have on local electric assets and the performance of surrounding regional electric networks. Local impacts are expressed in terms of the number of assets (under various equipment categories) most likely to be damaged. The total megawatt equivalent of damage-prone power plants is assessed, as is an estimate of power flows that could be disrupted. Damage functions and fragility curves are employed to identify specific electric assets that could be affected. The potential of large-scale electric system collapse is explored via a series of network simulations. The methodology employs two models, the FEMA-developed HAZUS MH-MR3 and Argonne-developed EPfast tool for simulating uncontrolled islanding in electric systems. The models are described, and their complementary roles are discussed.
\end{abstract}

\section{INTRODUCTION}

This paper reflects recent work performed for the Federal Emergency Management Agency (FEMA) Region V Disaster Operations Division in Chicago, Illinois, by Argonne National Laboratory. Argonne was tasked to estimate the impacts on electric assets and pertinent wide-area electric system operations that could result from simultaneous New Madrid and Wabash Valley seismic events. Region V includes the states of Illinois, Ohio, Michigan, Indiana, Wisconsin, and Minnesota.

Concerns about the recurrence of a major seismic event heightened in recent months because of the "200-year-recurrence cycle" (some studies cite 300-, 500-, and 700-year recurrence cycles, with varying degrees of probability) associated with the New Madrid Fault. A series of more than 2,000 earthquakes were felt by the few pioneers who lived in the region in 1811 and 1812. Some of the strongest were "recorded" at magnitudes of 7.7 in the New Madrid Seismic Zone (NMSZ) and 6.8 in the Wabash Valley Seismic Zone (WVSZ). This information indicates that it would be prudent for disaster response agencies like FEMA to prepare for such potentially devastating events and to estimate the impacts they might have on emergency response organizations.

A brief review of the literature indicates that a number of studies were done on the impacts of a major New Madrid seismic event in the Midwest (Corbet et al. 2007; Elnashai et al. 2008). These studies were found to be somewhat lacking in details on the impacts to specific types of electric assets and subsequent 
rippling effects to surrounding utilities (i.e., networks not directly within the seismic zones). FEMA commissioned this study with four primary objectives:

- Identify high-voltage (230- to 745-kilovolt or $\mathrm{kV}$ ) transmission lines, substations, and power plants that are at risk for potential damage;

- Examine the impacts of equipment damage and estimated procurement times for damaged key components;

- Identify components needing long lead times and possible sources of supply; and

- Estimate downstream impacts on FEMA Region V states.

In the statement of work (SOW) that FEMA provided to Argonne, FEMA defined the scenario to be simulated, as follows. The seismic event would occur on February 24 at 2:00 a.m. The NMSZ would exhibit a magnitude 7.7 earthquake that would occur in southern Illinois. The northern arm of the New Madrid Fault would rupture over a distance of tens of miles, generating intense shaking in southern Illinois and the boot heel of Missouri accompanied by a magnitude 6.8 earthquake along the Wabash Valley, with an epicenter located at $38.45 \mathrm{~N}$ and $87.89 \mathrm{~W}$ at a depth of 14.2 miles. The SOW tasked Argonne to determine the impacts as outlined and as implied by the four primary objectives. Figure 1 shows the general location of the NMSZ and WVSZ (Portante et al. 2009).

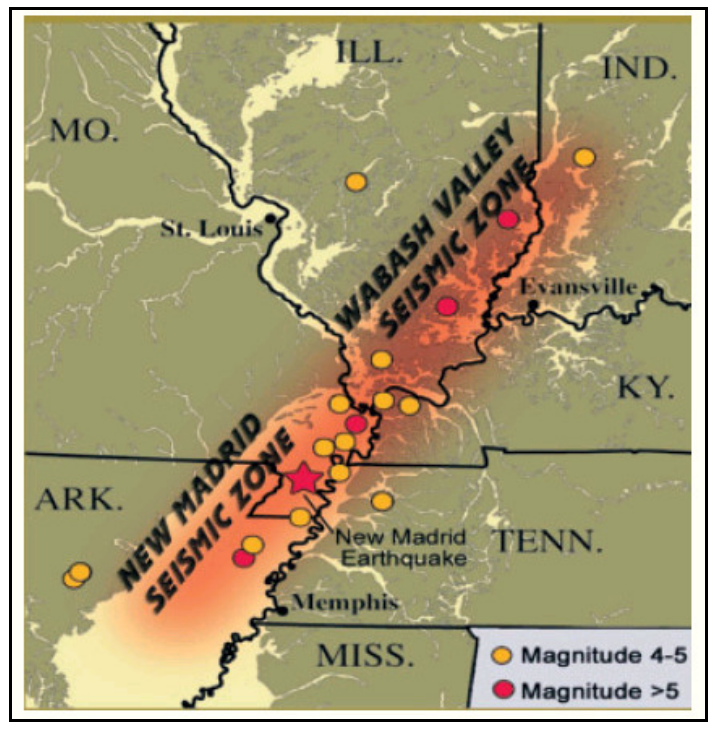

Figure 1: Location of NMSZ and WVSZ

\section{METHODOLOGY}

\subsection{Data and Simulation Model Requirements}

To accomplish the goals of the study, Argonne identified and assembled data sets, damage functions, and simulation models. The first data requirement pertains to earthquake hazards data: specifically, ground motion contours associated with the indicated events. To support the project, FEMA gave Argonne three sets of ground motion data. The sets include:

- Peak ground velocity (PGV) shake map,

- Peak ground acceleration (PGA) shake map, and

- Ground liquefaction map. 
The PGV data set is relevant for determining the number of leaks and breaks associated with buried pipeline systems. The PGA set is relevant for assessing damage to vertical structures, such as buildings, towers, and electric substations. The liquefaction maps are important for identifying areas where the soil that is underneath the pertinent support structures could liquefy, cave in, and create damaging sink holes.

The second data requirement pertains to the inventory data sets for transmission lines, substations, and power plants that are in the vicinity of the fault lines. Argonne provided the needed data sets for this requirement largely on the basis of information contained in Platt's PowerMap. Data on electrical load flow were also needed to model the high-voltage network surrounding the seismic zone and the systems encompassing the states in Region V. The load flow data were needed as input for the EPfast model to simulate system behavior. The Federal Energy Regulatory Commission (FERC) provided the pertinent load flow data covering Reliability First Corporation (RFC), Mid-west Reliability Organization (MRO), Southeastern Electric Reliability Council (SERC), and Southern Power Pool (SPP).

The third data requirement pertains to damage functions and models that can simulate direct damage to transmission lines, substations, and power plants located within the seismic zone. The damage functions were taken from the HAZUS MH-MR3 (or simply HAZUS) model. Thus, Argonne chose two simulation models to employ in the study: (1) HAZUS, a multihazard loss estimation earthquake model, and (2) EPfast, a tool for simulating uncontrolled islanding in electric systems. These two models are described in the following sections.

\subsection{HAZUS Model}

FEMA developed HAZUS to assess potential equipment and building losses due to earthquakes. It is primarily intended to simulate damage in the local area surrounding the earthquake's epicenter. It is designed to produce loss estimates for federal, state, regional, and local governments to use in planning for earthquake risk mitigation and emergency preparedness, response, and recovery. The methodology deals with nearly all aspects of the built environment and a wide range of different types of losses. Extensive national databases are embedded within HAZUS, and they contain various types of information, such as the demographic aspects of the population in a study region, square footage for different occupancies of buildings, and numbers and locations of bridges. Embedded parameters have been included as needed. Users can apply this information to make general loss estimates for a region. The HAZUS methodology and software are flexible enough so that locally developed inventories and other data that more accurately reflect the local environment can be substituted, resulting in increased accuracy (FEMA 2003).

In HAZUS, damage functions are given for each predefined damage state for substations (Table 1) and power plants. A quite different function is employed for transmission line towers. The different damage states for substations are given specific definitions. High-, medium-, and low-voltage substations are also referred to as " $500-\mathrm{kV}$ and above substations", "230-kV to $499-\mathrm{kV}$ substations", and " $115-\mathrm{kV}$ to 229-kV substations", respectively.

PGA is usually expressed in units of "g," the earth's gravitational acceleration, which is roughly equal to 9.806 meters per second per second or $32 \mathrm{ft} / \mathrm{sec}^{2}$. The median PGA is an important value because it indicates the point at which one damage state transitions to another. In some literature, this point is called the seismic capability of the equipment for a certain damage level (Oikawai et al. 2001). The $\beta$ symbol in Table 1 represents the standard deviation of a log-normal distribution (also called a fragility curve) associated with a particular damage state. $\beta$ is an estimate that accounts for other unknown factors that affect the accuracy of the functions and that has an impact on the determination of the median PGA in the process of deriving the fragility curves. HAZUS also provides definitions of damage states for power plants similar to those shown in Table1. Damage state definitions for power plants are quite different from those for substations. 
Table 1: Damage algorithms for substations based on HAZUS formulation (FEMA 2003).

\begin{tabular}{|c|c|c|c|}
\hline \multicolumn{4}{|c|}{ Peak Ground Acceleration } \\
\hline Classification & Damage State & Median $(\mathrm{g})$ & $\begin{array}{c}\text { Standard Deviation } \\
(\beta)\end{array}$ \\
\hline \multirow{3}{*}{ Low voltage } & Slight/minor & 0.15 & 0.70 \\
& Moderate & 0.29 & 0.55 \\
& Extensive & 0.45 & 0.45 \\
& Complete & 0.90 & 0.45 \\
\hline \multirow{4}{*}{ Medium voltage } & Slight/minor & 0.15 & 0.60 \\
& Moderate & 0.25 & 0.50 \\
& Extensive & 0.35 & 0.40 \\
& Complete & 0.70 & 0.40 \\
\hline \multirow{3}{*}{ High voltage } & Slight/minor & 0.11 & 0.50 \\
& Moderate & 0.15 & 0.45 \\
& Extensive & 0.20 & 0.35 \\
& Complete & 0.47 & 0.35 \\
\hline
\end{tabular}

\subsection{EPfast Model}

EPfast is a linear steady-state model for simulating the uncontrolled islanding of large power systems due to power disruptions that result from the loss of a single transmission line or a group of lines in conjunction with the simultaneous loss of generation. Downstream impacts are estimated by calculating the amount of electric load shed on the various substations in the network, which are part of the islands formed as a result of the fragmentation of the electric grid. The tool identifies the substations that can experience a loss of power as well as the quantity of power lost. Based on past events, the number of affected customers is estimated by assuming a customer density index that usually ranges from 400 to 800 customers per megawatt (MW) lost.

The EPfast model explores the possibility of uncontrolled islanding caused by successive (i.e., cascading) steady-state line overloads initially triggered by a major, non-reclosable, line-to-line fault or simply by a de-energization of a major line due to a seismic event or other natural causes. EPfast estimates the extent of electrical disturbance that a seismic event (such as a New Madrid seismic event) can cause. For the unfamiliar, islanding is simply the process in which a big network breaks into pieces of smaller networks usually resulting in large service outages. In this simple logic, several assumptions are made:

1. A steady-state system condition is assumed. The effects of transient power swings, transient frequency variations, and transient voltage variations are neglected.

2. Whenever line overloading occurs, the line is assumed to be open and to remain open until a major restoration effort is conducted. During the initial and the ensuing line openings, the load levels and generator outputs throughout are assumed to remain constant until the system breaks into island grids.

3. When the system splinters into several island grids (as a result of cascading overloads), the following assumptions are made:

a) Island grids that do not have power sources are assumed to be fully disrupted and under total blackout.

b) Island grids with power sources are assumed to be able to adjust either their loads (via automatic load shedding) or their generator outputs (i.e., via output reduction) to settle to a new balanced operating point. 


\section{Portante, Kavicky, Folga, Wulfkuhle, Craig and Talaber}

c) The redispatching, as well as the balancing of generation and load within the island grids can be done by invoking an optimal dispatching program or following simple heuristics.

The results obtained from EPfast simulations are conservative, generally underestimating the impacts of major faults or disruptions. Impacts of accompanying transient events, such as frequency decay, voltage collapse, power swings, and related instability problems, could be several times more severe than impacts caused by cascading line overloads alone.

There are several reasons for using a steady model to assess a seismic event which is obviously transient. First, electric transient models (or dynamic models) require the use of proprietary data (e.g., machine constants of generators, and specific feedback control schemes) which is impossible to obtain. In addition, the cost of developing or obtaining a transient model would be prohibitive. The steady state approach, on the other hand, is a simplified method requiring non-exact input values and much less amount of data. The steady state approach is useful for determining the general direction of the outcome (e.g., collapse or not collapse), rather than the precise quantitative results.

\subsection{Methodology and Analysis Procedures}

The portion of the methodology involving the use of HAZUS fragility curves is straight forward. The electric infrastructure layers (i.e., transmission lines, substations, and power plants) were superimposed on the seismic footprint provided by FEMA. The potential of the various electric components for seismic damaged was then assessed using the fragility curves as a function of the ground shaking intensity.

For the portion involving the use of EPfast, the methodology requires the creation of the following cases:

- Base case: Defines the status of the network prior to the event.

- Case 1: Defines the status of the network, assuming all earthquake-damaged equipment is not operational. The network would typically experience a supply-demand imbalance as a result of the initial outages (due to structural damage) caused by operational problems like line overloads.

- Case 2: Defines the status of all the networks and island grid after all overloaded lines in Case 1 are assumed to be nonoperational.

- Case N: Defines the status of additional cases covering the hundreds of island grids that could be further formed as a consequence of the spiraling system collapse.

Note that as each island grid is formed, a quick supply-demand balance is assumed by either shedding excess load or shutting down surplus generators. The associated generation dispatch, however, is non-optimal (because EPfast does not yet have an optimal dispatch program). This condition can result in line overloads and thus further line outages. EPfast toggles between its load flow and islanding analysis modules (IAMs) during this iterative process without executing an optimal power flow program.

The steps in the methodology are as follows:

1. Define scenario, set assumptions, gather shake maps, gather electric asset inventory, and assemble wide-area load flow data.

2. Identify set of high-risk transmission lines, substations, and power plants.

3. Assess local damage.

4. Run pre-disruption EPfast load flow (base case).

5. Run post-disruption EPfast load flow (Case1). Assume all damaged assets are out of service. 
6. Identify overloaded lines. Assume overloaded lines are inactive. Run EPfast load flow (Case 2).

7. Check if the system splintered into island grids. If not, Stop and generate report (no islanding occurred). Otherwise, proceed to Step 8.

8. Balance supply with demand for each island grid. Perform load flow for each balanced island grid.

9. Check if all island grids have been stabilized (i.e., balanced without line overloads). If not, repeat Step 8. Otherwise, end calculations and generate report.

\section{INPUT DATA DESCRIPTION}

\subsection{FEMA Shake Maps}

A shake map is another term used to refer to ground motion data. The PGV contours were provided by FEMA for New Madrid and Wabash Valley. The contoured PGA and liquefaction maps for the two areas were also made available by FEMA. Contoured shake maps are also called simplified shake maps because they levelize the PGV or PGA values over an entire zone or layer surrounding the epicenter.

\subsection{Electric Asset Inventory}

Substation, transmission line, and power plant data were taken from Platt's PowerMap. PowerMap is a commercial geospatial information system (GIS) that contains spatial and tabular information on the electric infrastructure for the entire United States. Data on the locations of towers are not publicly available, so it was assumed that the towers along a transmission line are spaced at regular intervals of 500 meters. There are hundreds of transmission lines directly above the seismic zones.

The focus of this current assessment is on five major types of power plants: oil, natural gas, coal, hydroelectric, and nuclear. These five types represent the top five conventional generation sources for the U.S. electric power industry. There are hundreds of power plants in the vicinity of the epicenter (including units below $20 \mathrm{MW}$ ).

\subsection{Load Flow Data}

Pertinent load flow data were provided by FERC for a winter off-peak case covering MRO, RFC, SPP, and SERC. These data sets were PTI (Power Technology International)-formatted, very detailed, and had information for $1.0-\mathrm{kV}$ to $750-\mathrm{kV}$ lines and substations. The load flow data thus presented a much finer inventory of assets than the inventory available from PowerMap. The RFC set (which covered most of the FEMA Region V eastern states) consisted of about 42,000 nodes with more than 100,000 lines. Because these FERC load flow data sets were normally decoupled with respect to territorial franchise (and MRO data were thus not computationally linked to RFC data), a modeling challenge arose as modelers worked to combine all regions into a single, seamless data set.

A second load flow data set (although of earlier date) was made available to Argonne. It was an integrated version that linked parts of MRO, RFC, SPP, and SERC together, with Illinois as the apparent center. This latter set consisted of about 17,000 nodes and was more manageable in the context of the project's budgetary constraints. To avoid data set integration complexities, this 17,000-node set was deemed appropriate for use in the EPfast simulation. Table 2 summarizes the major features of this data set. The large size of the network for the simulation necessitated the use of MATLAB to speed up calculations. Thus the entire uncontrolled islanding assessment process may be called a MATLABassisted EPfast solution. Note that the 17,000-node set was later adjusted to reflect winter off-peak conditions and ensure a well-conditioned base case. 
Portante, Kavicky, Folga, Wulfkuhle, Craig and Talaber

Table 2: Description of raw NERC data used for simulation.

\begin{tabular}{|l|c|}
\hline \multicolumn{1}{|c|}{ Attributes } & Description or Quantity \\
\hline A. General & RFC, SPP, MRO, SERC \\
\hline NERC regions partially covered & Summer peak day \\
\hline Simulation case description & 150,000 \\
\hline B. Supply-demand (MW) & 151,140 \\
\hline Peak-day load & 100,000 \\
\hline Peak-day generation & 17,146 \\
\hline Estimated off-peak load & 31 \\
\hline C. No. of buses & 197 \\
\hline Total & 592 \\
\hline $765-\mathrm{kV}$ buses & 1,618 \\
\hline 500-kV buses & 3,221 \\
\hline 345-kV buses & 4,135 \\
\hline 230-kV buses & 991 \\
\hline $115-\mathrm{kV}$ buses & 6,361 \\
\hline $69 \mathrm{kV}$ buses & 1,670 \\
\hline 34.5 kV buses & 469 \\
\hline$<34.5 \mathrm{kV}$ & 37,829 \\
\hline Active gen buses & 15,722 \\
\hline Inactive gen buses & \\
\hline D. No. of lines and transformers & \\
\hline Total lines & \\
\hline Total transformers & \\
\hline \multicolumn{2}{|c|}{} \\
\hline
\end{tabular}

\section{MAJOR ASSUMPTIONS}

Five major assumptions pertain to the electric transmission system assessment:

- Events occur on February 24 at 2:00 a.m.

- Loading levels of transmission lines are about 50-60\% of peak power flows.

- February is a relatively low-demand month in terms of electrical load in all regions of NERC.

- A failure of a substation would cause its associated transmission lines to de-energize and interrupt operations.

- Power plants and transmission facilities will shut down once a moderate damage state is reached.

The assumption on the timing of the event was specified by FEMA. If the event were assumed to happen in August when electric demand is high, the potential impact is certain to be more disastrous.

\section{RESULTS AND RELATED DISCUSSIONS}

\subsection{Local Electric Assets}

The quantity and megawatt equivalent of the electric assets that would be directly and instantly damaged by the earthquake are summarized below: 


\section{Portante, Kavicky, Folga, Wulfkuhle, Craig and Talaber}

- The combined NMSZ and WVSZ events could de-energize at least 111 high-voltage lines and 84 substations (on the basis of PowerMap's inventory). A much larger quantity was revealed when the FERC-provided load flow data were considered, particularly the data that pertained to equipment with voltage ratings of $230 \mathrm{kV}$ or less. More specifically, when including all voltage levels, the load flow data indicated that about 760 lines and 615 buses could be directly impacted. Figure 2 shows the locations of high-risk, high-voltage transmission lines based on the PowerMap inventory.

- The combined events could potentially cause physical damage to about 170 to 200 high-voltage towers. Most of these towers are located along or near the New Madrid fault lines. Most towers are 500-kV structures, and the associated lines are included in the 111 disrupted high-voltage line count. Furthermore, FERC's load flow data revealed that more lower-voltage towers could fail around the fault lines.

The combined events could potentially directly affect a large number of oil, natural gas, coal, and hydroelectric plants, with a total combined capacity of about 25,000 MW. (The actual operational level of the power plants, however, might be lower than this due to maintenance or unit commitment considerations). No nuclear power plants were found to be at risk of being damaged by the earthquake. The complete listing of the identified damaged electric equipment is contained in Argonne's report to FEMA (Portante et al. 2009).

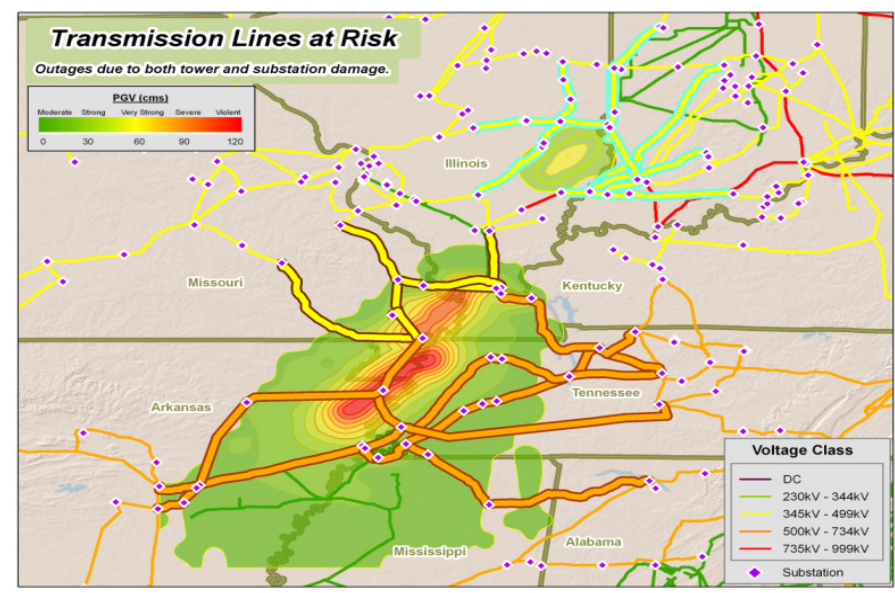

Figure 2: High-risk transmission lines in the vicinity of NMSZ and WVSZ (Platts PowerMap 2007)

\subsection{Load Flow Results, System Collapse, and Customers Affected}

The results of the MATLAB-assisted EPfast load flow simulations confirmed that with the simultaneous outage of assets described above, the system encompassing the Region V states and beyond would splinter into numerous island grids. The manner of fragmentation of the base system appeared to be a complete disintegration and total network collapse as the system splintered into hundreds of isolated grids.

At the instant of the seismic event (Case 1), the initial outage of the directly affected lines and substations caused a load loss of about 9,100 MW and splintered the original grid into 410 separate grids (762 lines and 615 nodes were made nonoperational directly because of the quake), according to the load flow data. The largest island was composed of 16,030 nodes, or about $6.5 \%$ smaller than the original network. The remaining nodes were mostly one-node island grids. However, this 16,030-node network was noted as having numerous overloaded lines. When these overloaded lines were assumed to be open, the 16,030-node grid splintered further into 572 isolated grids, as shown in Table 3 (Case 2). Table 3 


\section{Portante, Kavicky, Folga, Wulfkuhle, Craig and Talaber}

shows that the combined effects of the ground movement and the ensuing line overloads caused an overall load reduction of at least 34\% (i.e., relative to the original system-wide loading of about 100,000 MW), assuming a quick supply-demand balance is attained for each of the 572 island grids. However, because generator dispatch is assumed to be non-optimal, each of the 572 island grids could further experience more line overloads and splinter again into secondary island grids. Thus, more loads could be lost, possibly up to $60 \%$ of the original load.

For Case 2 (Table 3), a total of 572 island grids was indicated by the analysis results, with the largest island exhibiting a load of only 19,832 MW. Table 3 shows the sizes of the 10 largest island grids in terms of the number of nodes and branches. The supply-demand balance in each island is also summarized. The island grids ranked from 11 to 572 are very small isolated networks and are assumed to be totally disrupted (total black out). Because of budget and time constraints, it was not possible to examine and simulate each of the 572 island grids.

Table 3: Characteristics of island grids.

\begin{tabular}{|c|c|c|c|c|c|c|c|c|c|c|}
\hline $\begin{array}{c}\text { Rank } \\
\text { by Size }\end{array}$ & $\begin{array}{l}\text { Island } \\
\text { ID }\end{array}$ & $\begin{array}{l}\text { No. of } \\
\text { Buses }\end{array}$ & $\begin{array}{c}\text { No. of } \\
\text { Branches }\end{array}$ & $\begin{array}{c}\text { Load } \\
\text { (MW) }\end{array}$ & $\begin{array}{c}\text { Gen } \\
\text { (MW) }\end{array}$ & $\begin{array}{c}\text { Load } \\
\text { Lost } \\
(\mathrm{MW})\end{array}$ & $\begin{array}{c}\text { Gen } \\
\text { Lost } \\
(\mathrm{MW})\end{array}$ & $\begin{array}{c}\text { Retained } \\
\text { Load } \\
(\mathrm{MW})\end{array}$ & $\begin{array}{l}\text { Retained } \\
\text { Gen } \\
\text { (MW) }\end{array}$ & $\begin{array}{c}\% \text { Load } \\
\text { Reduction }\end{array}$ \\
\hline 1 & 0 & 3,694 & 4,631 & 19,832 & 24,013 & 0 & 4,181 & 19,832 & 19,832 & \\
\hline 2 & 294 & 3,170 & 3,636 & 7,464 & 12,454 & 0 & 4,990 & 7,464 & 7,464 & \\
\hline 3 & 44 & 3,108 & 3,865 & 29,946 & 28,194 & 1,752 & 0 & 28,194 & 28,194 & \\
\hline 4 & 396 & 1,192 & 1,340 & 3,564 & 3,388 & 176 & 0 & 3,388 & 3,388 & \\
\hline 5 & 335 & 1,041 & 1,190 & 2,025 & 3,431 & 0 & 1,406 & 2,025 & 2,025 & \\
\hline 6 & 151 & 396 & 439 & 2,568 & 3,419 & 0 & 851 & 2,568 & 2,568 & \\
\hline 7 & 516 & 261 & 296 & 2,224 & 2,034 & 190 & 0 & 2,034 & 2,034 & \\
\hline 8 & 517 & 189 & 226 & 821 & 378 & 443 & 0 & 378 & 378 & \\
\hline 9 & 316 & 153 & 172 & 118 & 116 & 2 & 0 & 116 & 116 & \\
\hline 10 & 397 & 147 & 160 & 359 & 306 & 53 & 0 & 306 & 306 & \\
\hline $11-572$ & 999 & 134 & 1,203 & 31,079 & 22,267 & 31,079 & 22,267 & 0 & 0 & \\
\hline Total & & 13,618 & 18,361 & 100,000 & 100,000 & 33,695 & 33,695 & 66,305 & 66,305 & $34 \%$ \\
\hline
\end{tabular}

The estimated overall percent reduction in load being served per region as a result of steady-state disruption is $34 \%$ (or 33,695 MW), as shown in Table 3. The dispersal of this load loss among the participating regions is shown in Table 4. Because only steady-state conditions were considered, the impacts shown in Table 4 underestimate the full extent of the impacts.

Table 4: Estimated reduction in load (i.e., loss of service) among the various participating regions as a result of NMSZ shaking, cascading steady-state overloads, and ensuing island grid formation. (Notes: Impacts could be much more severe when effects of transient instability are factored in the analysis.)

\begin{tabular}{|l|l|c|c|}
\hline \multicolumn{1}{|c|}{ Region } & \multicolumn{1}{|c|}{$\begin{array}{c}\text { States Included in } \\
\text { in Load Flow Model }\end{array}$} & $\begin{array}{c}\text { Estimated \% } \\
\text { Reduction } \\
\text { in Load }\end{array}$ & $\begin{array}{c}\text { \% Share } \\
\text { of Total } \\
\text { Load Lost }\end{array}$ \\
\hline Central & IA, NE & 26 & 17 \\
\hline Midwest & IN, IL, OH, MN, WI & 45 & 31 \\
\hline Northeast & DC, MD, NJ, NY, PA, VA & 57 & 38 \\
\hline Southeast & AL, FL, KY, GA, MS, NC, TN & 18 & 13 \\
\hline Southwest & AR, OK, TX & 1 & 1 \\
\hline Total & 34 & 100 \\
\hline
\end{tabular}

Capturing the full extent of the impacts of an electrical disturbance as catastrophic as the NMSZ and WVSZ events requires the consideration of other real factors (besides line overloads), such as the effects of transients (voltage collapse and frequency decays), and power swings. It also requires the consideration 
of the various mitigating measures available to electric utilities, such as directed load shedding, fault protection schemes, power system stabilizers, and automatic islanding plans. However, with the application of proper heuristics, such considerations can be imputed into the impact description defined by EPfast.

One heuristics-based approach was to assemble the top major electrical outage events in the United States and examine the dynamics (i.e., cause and effect) that governed them. Table 5 summarizes the top five major blackout events in the United States.

Table 5: Summary of major blackout events in the United States.

\begin{tabular}{|l|c|c|}
\hline \multicolumn{1}{|c|}{ Event Name } & MW lost & $\begin{array}{c}\text { No. of People } \\
\text { Affected } \\
\text { (millions) }\end{array}$ \\
\hline Aug. 14, 2003, Northeast U.S.-Canada Blackout & 61,800 & 50.0 \\
\hline Aug. 10, 1996, WSCC Blackout & 30,500 & 22.5 \\
\hline Nov. 9, 1965, Northeast U.S.-Canada Blackout & 37,080 & 30.0 \\
\hline July 2, 1996, WSCC Blackout & 12,000 & 8.9 \\
\hline Dec. 22, 1982, West Coast Blackout & 12,350 & 5.0 \\
\hline
\end{tabular}

Note that the worst outage event in U.S. history (Aug. 14, 2003, blackout) was triggered by the failure of only two 345-kV lines (Stuart-Atlanta and Harding-Chamberlin lines) and the outage of a 597-MW power plant (Eastlake 5). The power plant outage took away the initial reactive support that eventually led to widespread voltage collapse in both Canada and the northeastern United States. Power plants are the primary source of reactive power in the system, and when a cluster of them abruptly disengages as the result of some event, a voltage deterioration is likely to ensue. The study determined that in the case of NMSZ and WVSZ seismic events, about 9,000 MW of operational power plant capacity is likely to go off line instantly. This situation implies a very large loss of reactive power, leading to widespread collapse. Combine that situation with more than 111 high-voltage lines tripping simultaneously, and a scenario that is more significant than the Aug. 14 blackout occurs. The steady-state simulation results and the supporting heuristics-based analysis led Argonne to the following conclusions:

- The impacts of the combined NMSZ and WVSZ events could far exceed the impact of the Aug. 14, 2003, Northeast U.S.-Canada blackout.

- This event could possibly affect 50-100 million people especially in states nearer to the earthquake's epicenter, with the Northeast and the Midwest regions likely to experience the brunt of the impact.

- Region V states could potentially experience a $45-100 \%$ reduction in power service, especially when adverse transient effects (e.g., frequency decay, voltage deterioration, large power swings) are considered.

- Many areas in FEMA Region V states could experience downtimes of at least 14 hours and up to 5 days, as experienced in the Aug. 14 blackout.

With regard to equipment procurement and replacement, a number of engineering firms were consulted, and they provided the following insights:

- The equipment with the longest lead time (8-12 months) is the transformer.

- In general, there are more approved suppliers for towers, switches, bushings, arresters and inductive reactors, implying that lead times would be shorter (1-4 months) for this equipment. 


\subsection{Validity of Results and EPfast Performance}

Because the current work in relation to the NMSZ is the first of its kind in terms of the intent and the scale of the electric network being simulated, validation by comparison or benchmarking with previous work may be difficult. In addition, the large number of uncertainties associated with any seismic event could cause results to vary substantially. With regards to EPfast performance, it took only 15 minutes to complete the simulation of a 17,000 node network.

\section{CONCLUSIONS}

The study has shown a viable methodology for simulating both the local and the downstream impacts from NMSZ and WVSZ events in relation to the electric systems operating in the vicinity of the earthquakes' epicenters and extending concentrically to FEMA Region V states and beyond. Assessing the full extent of the impact on the electric system is complex and requires the consideration of transient events, such as frequency decays, voltage collapse, and generator-tripping power swings. It also requires the consideration of the various mitigating measures available to electric utilities, such as load shedding, fault protection schemes, and automatic controlled islanding plans. The use of a heuristics-based assessment to supplement steady-state simulations can result in a reasonable quantification of the overall impacts. On the basis of this approach, the study has shown that electric systems surrounding the NMSZ and WVSZ would collapse and splinter into numerous island grids. The results further show that the Northeast and the Midwest regions would be most likely to experience the brunt of the impact.

\section{ACKNOWLEDGMENTS}

The authors wish to acknowledge the contributions of the following organizations: Argonne's Infrastructure Assurance Center (IAC) for providing technical and logistical support and the FEMA Region V Disaster Operation Division for providing the hazard data and funds for the project. Special thanks go Jim Peerenboom and Ron Fisher of IAC for facilitating administrative approval during the various phases of the project. The authors also wish to thank the following Argonne personnel for providing needed computer and MATLAB support: Pamela Sydelko, Charles Macal, and Dan Miller. Appreciation also goes to Michael McLamore for coordinating the meetings with EN Engineering to obtain estimates of procurement times for replacing pertinent electric assets.

The submitted manuscript has been created by UChicago Argonne, LLC, Operator of Argonne National Laboratory ("Argonne"). Argonne, a U.S. Department of Energy Office of Science laboratory, is operated under Contract No. DE-AC02-06CH11357. The U.S. Government retains for itself, and others acting on its behalf, a paid-up nonexclusive, irrevocable worldwide license in said article to reproduce, prepare derivative works, distribute copies to the public, and perform publicly and display publicly, by or on behalf of the Government

\section{REFERENCES}

Corbet, T.F., J. Ellison, S.E. Jordan, and R. Taylor. 2007. NISAC infrastructure analysis: Impact of a large earthquake in the New Madrid Earthquake Zone on national energy infrastructure. Sandia National Laboratories, Albuquerque, New Mexico, December.

Elnashai, A. S, L.J. Cleveland, Theresa Jefferson, and John Harrald, 2008. Impact of earthquakes on central U.S.A. Mid America Earthquake Center, sponsored by Federal Emergency Management Agency, December.

FEMA (Federal Emergency Management Agency). 2003. HAZUS-MH MR3 technical manual. Mitigation Division, Washington, D.C. 
Oikawai, T., S. Fukushima, H. Takase, T. Uchiyama, and K. Muramatsu. 2001. Seismic reliability evaluation of electrical power transmission systems and its effect on core damage frequency. Paper No. 156, Transaction SMiRT 16, Washington, D.C., August.

Portante, E., S. Folga, B. Craig, M. McLamore, S. Shamsuddin, V. Hammond, L. Talaber, and J. Kavicky. 2009. New Madrid Seismic Zone support studies: Identifying affected electric transmission and generation facilities and assessing impacts on gas pipelines. Final Report, Federal Emergency Management Agency Region V, Disaster Operations Division, Chicago, Illinois, June.

Platts PowerMap. 2007. A strategic desktop mapping system. The McGraw Hill Companies (http://www.platts.com).

\section{AUTHOR BIOGRAPHIES}

EDGAR C. PORTANTE is an energy systems engineer at Argonne National Laboratory. His research interests include performance and vulnerability assessments of energy systems, including electric power and natural gas. He earned a Masters degree in Electrical and Computer Engineering from Illinois Institute of Technology, a Master of Management degree from Asian Institute of Management, and an M.S. degree in Power Systems Engineering from the University of the Philippines. His e-mail address is <ecportantedanl.gov>.

JAMES A. KAVICKY has a Ph.D. in Electrical Engineering (Power Systems) from Illinois Institute of Technology. He works as an energy systems engineer at Argonne National Laboratory's Infrastructure Analysis and Assessments Group. He has provided his expertise on electric power, natural gas, and other infrastructures for reports for the U.S. Department of Homeland Security, U.S. Department of Defense, and U.S. Department of Energy. His e-mail address is <kavickyeanl.gov $>$.

STEPHEN M. FOLGA is a Senior Systems Engineer at Argonne National Laboratory and focuses his research on natural gas and petroleum systems modeling and analysis. He is the manager of the Energy Systems Analysis and Assessment branch of the Infrastructure Assurance Center at Argonne. He earned a Ph.D. in Gas Engineering and a B.S. degree in Chemical Engineering from Illinois Institute of Technology. His e-mail address is < sfolgaeanl gov $\rangle$.

GUSTAV R. WULFKUHLE is the Chief Operational Planner at the Response Operations Branch, Disaster Operations Division of Region V, Federal Emergency Management Agency headquartered in Chicago, Illinois. Mr. Wulfkuhle oversees the development of disaster and recovery plans for FEMA Region $\mathrm{V}$ and directs the annual workshop for emergency response planning. His e-mail address is <Gustav.Wulfkuhle@dhs.gov>.

BRIAN A. CRAIG is a software engineer at Argonne National Laboratory. His work focuses primarily on the development of computer simulation models for various energy and supply-chain systems. He earned a B.S. and an M.S. in Computer Science from North Central College in Illinois. His e-mail address is <bcraigeanl.gov>.

LEAH E. TALABER works at Argonne National Laboratory in the Energy Systems Analysis and Assessment branch of the Infrastructure Assurance Center. The core of her work involves geospatial analysis of critical infrastructure in the energy sector. Talaber earned a B.S. degree in Geography and Geographical Information Sciences (GIS) from Elmhurst College. Her e-mail address is $<$ ltalabereanl.gov>. 